could record the impressions that have led me to think that despite the conclusions quoted above deputizing services probably do not provide the best patient care. The only drugs we were given were morphine, pethidine, adrenaline, aminophylline, ergometrine, amylobarbitone sodium, A.P.C., and free samples, which were usually of the less commonly indicated antibiotics. Many of the deputies bought their own supplies of other drugs; the rest did without. We were told to equip ourselves with a sphygmomanometer, auriscope, and ophthalmoscope, bur it was not checked whether we had these items and in fact some of the deputies did not.

Many patients were upset at not seeing the doctor they thought they had called, and in the cases of children and the elderly I think the history and examination were made more difficult by unfamiliarity. Many were annoyed by having to make several telephone calls. They often rang their own G.P., were told he was off duty, told to ring another doctor, and when they rang him were referred to the deputizing service. Those that had to use public call boxes found this particularly trying. Our service accepted reverse-charge calls, but not all patients knew how to make use of this facility.

Many patients I saw were old, chronically sick, living in poor conditions, and relatively inanticulate. Seeing these people for the first time, it was very difficult to decide whether their condition had undergone any recent change or not. It was not possible to arrange a second visit unless the patient rang again and asked for it. I understand that many services allow a deputy to make a second call, for examole, at weekends - but I was told that we could not do this and that if I thought a patient should be seen again, then he should be admitted to hospital.

From my experience in hospital I have many times wished that I had had access to the records of patients admitted as emergencies. Some patients do not know what drugs they take, and in the case of steroids, monoamine oxidase inhibitors, digoxin, and antibiotics this is often important. Again, some patients do not know what operations they have had, which may be of crucial importance if they present with, for example, an acute abdomen.-I am, etc.,

Welsh National School of Medicine,

D. H. Howe

Welsh National School
Gereral Practice Unit,
Cardiff

1 Williams, B. T., Dixon, R. A., and Knowelden, Medicine, 1973, 27, 126. Preventive and Social

\section{Prepacked Milk Feeds for Continuous} Intragastric Feeding

SIR,-In a paper describing the use of continuous intragastric milk feeds in infants of low birth weight (2 September 1972, p. 547) it was suggested that the sterile milk should be placed in an autoclaved blood transfusion bottle. Since the publication of that paper prepacked feeds have been introduced in many maternity units, milk kitohens have been abolished, and there are no facilities for providing sterile milk in blood transfusion bottles. We have found that continuous intragastric feeds can be given using prepacked feeds by substituting a standard blood transfusion bottle bung for the feeding teat (see fig.).

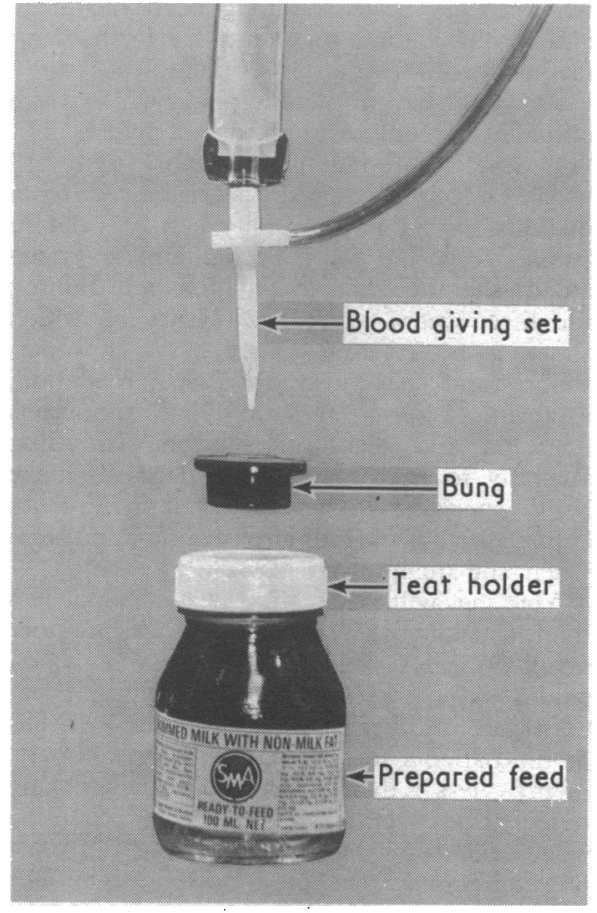

The bung is inserted into the plastic teat holder and both can be easily sterilized by autoclaving. The bung is pierced by a sterile standard blood giving set, which is attached to the feeding tube. A simple bottle holder can be constructed from metal wire.-We are, etc.,

John Wyeth and Brother Ltd.,

G. A. FAUX Taplow, Berks

Northwick Park Hospital,

H. B. Valman

Harrow, Middlesex

\section{Polyvinyl Chloride T-tubes}

SIR,-The loss of flexibility in a polyvinyl chloride T-tube described by Wing Commander M. W. Sleight (21 July, p. 171) can indeed occur within 10 days of operation as the following case report demonstrates.

A woman underwent elective cholecystectomy in October 1972. Preoperative cholangiography showed stones in the common bile duct, which were removed via a choledochotomy. The common bile duct was drained with a polyvinyl chloride (Portex) T-tube. The subhepatic area was drained by a right flank, corrugated polyvinyl chloride drain. The initial postoperative course was uneventful, the flank drain being removed on the fifth day. On the ninth postoperative day $T$-tube cholangiography showed no residual stones and free flow into the duodenum. On the following day the T-tube was removed with difficulty, whereupon the patient complained of severe adbominal pain and very rapidly developed signs of generalized peritonitis. Urgent laparotomy confirmed the diagnosis of biliary peritonitis. The additional features of interest were the absolute lack of a track to either drain site and the hole in the common bile duct, which was now considerably larger than the original opening. The common bile duct on this occasion was drained by means of a red rubber $T$-tube and the abdomen by a red rubber corrugated drain. The postoperative course was uneventful and the patient continued to be well 10 months later.

The polyvinyl chloride $T$-tube on examination showed an interesting pattern of change. The portion of tubing which had remained outside the body was still flexible and pliable, the remainder was rigid and non-pliable. The line of demarcation was quite distinct. It is unlikely, therefore, that the action of bile was responsible for the alteration. Similar changes have been observed in nasogastric tubes, admittedly after a longer period.' Polyvinyl chloride T-tubes are unsuitable for use because of their failure to promote a fistulous track and also because of the very real danger of damage to the common bile duct during removal.

There have been several reports of toxic effects ascribed to substances leached out of polyvinyl chloride. ${ }^{24}$ These have led to calls for new safety standards. ${ }^{25-7}$ Any standands specification must also consider the purpose for which the plastic is intended.8 It would therefore appear desirable that in addition to the study of the effects of the body on prosthetic materials 89 the effects of such materials altered by the body on important structures be urgently examined. One such area that immediately comes to mind is the use of polyvinyl chloride tracheostomy tubes and the incidence of tracheal stenosis. $10 \mathrm{II}$ -I am, etc., St. Vincent's Hospital,
Dublin

D. J. BOUCHIER-HAYES

1 Melsom, H., Lancet, 1971, 1, 87

Duke, H. N., and Vane, J. R., Lancet, 1968, 2, 21.
Rogers, A. F., and Dunn, P. M., Lancet, 1969, 2 ,
1246 . Jacgar, R. J., and Rubin, R. J., New England Jagar, R. J Jis and Rubin, R. J., New

5 Little, K., and Parkhouse, J., Lancet, 1962, 2, 857. 7 Lancet, $1968,2,34$.

8 Little, K., Lancet, 1968, 2. 351

Tote, C. R., British Medical foumal, 1973, 3, 10 Guess, W. L., and Stetson, J. B., Fournal of the American Miedical Association, 1968, 204,580 . Andrews, M. J., British Foumal of Surgery, 1971,

\section{Facial Palsy in Tetanus}

SIR,-I read with interest the report of a case of facial palsy in tetanus by Drs. M. Mishra and B. N. Sinha (19 August, 1972, p. 475). They thought that a neuromuscular block may be responsible for such paralysis as only the lower part of the face was involved in their case. Boudouresques et al.,1 mentioned that the facial palsy may be limited to the upper or lower part of the face or a single muscle may be affected.

Kaeser et al.,2 reported a case of generalized tetanus in which $5 \mathrm{mg}$ of D-tubocurarine intravenously every 20 minutes was used for muscle relaxation. The patient remained tetraolegic after the ourare was discontinued and developed severe diarthoea, hypotension, and bronchopneumonia and subsequently died. On the basis of electrophysiological studies they suspected neuromuscular block by tetanus toxin as the cause of tetraplegia. Kaeser and Saner ${ }^{3}$ reported neuromuscular block in experimental local tetanus in rats due to impaired presynaptic release of acetylcholine. There is considerable controversy as to whether the lesion is in the facial nucleus or peripheral nerve or at the neuromuscular junction. A peripheral nerve lesion was suggested by Watkins $^{4}$ on the basis of loss of taste on the same side as the facial palsy. Starzecka ${ }^{5}$ reported an incidence of $3.57 \%$ of facial palsy in their 757 cases. Park ${ }^{6}$ reported six cases $(5.6 \%)$ of facial paralysis out of 107 cases of tetanus. Farquharson ${ }^{7}$ reported one case (which I saw while working in Brook 